\title{
Evaluation of cardiac function in patients with thalassemia intermedia: A prospective hospital based study
}

\author{
Zahraa Elsayed Ahmed 1, Safaa Hussein Ali 2, Walaa Mostafa Madkoor 3. \\ 1professor,head of Pediatric haematology Unit, Pediatric Department,Faculty of \\ Medicine, Sohag University, Sohag, Egypt. \\ 2 Assistant professor,Pediatric Department, Faculty of Medicine,Sohag \\ University, Sohag, Egypt. \\ 4 Specialist, Pediatric Department,Faculty of Medicine, Sohag University, Sohag \\ Egypt. \\ Type of article: Original
}

\section{Abstract}

Background:B-Thalassemia is an inherited hemoglobin disorder caused by impaired synthesis of the b-globin chain and resulting in chronic hemolytic anemia.In the absence of regular treatment of thalassemia intermedia patients the diastolic performance of the left ventricle is maintained stable, while the pressure of pulmonary arteries continues to rise which is the main cause of death in these patients. 2D, $M$ mode echocardiographyand tissueDopplerare method for evaluating the cardiac function in patients with thalassemia intermedia.

Objective: Our main objective in this study is to evaluate the cardiac function in patients with thalassemia intermedia by 2D, M mode echocardiography and Doppler methods.

Methods: This case-control study was conducted on 46 thalassemic patients (mean age: $9.7 \pm$ 4.6years) and 46 healthy individuals (mean age: $10.3 \pm 4.1$ years) as a control group from October 2016 toSeptember 2017 in the Pediatric haematology Clinics and inpatients of Pediatric Department.There was no sign of cardiac involvement by physical examination, chest x-ray and ECG in patients. Echocardiographic parameters were measured in groups, and finally data was analyzed by SPSS software.

Results:The mean of left ventricular myocardial performance index (LMPI) ((Pvalue $<0.001)$ and left ventricular mass index $(\mathrm{LVMI})((\mathrm{P}-$ value $<0.001)$ have statistically significant differencebetween two groups. Mean of interventricular septal dimension in diastole (IVSD), left ventricular posterior wall thickness in diastole (LVPWD) and interventricular septal dimension in systole (IVSS) were also statistically significant with a Pvalue of, $<0.001,0.042,<0.001$ respectively. Ejection fraction (EF) (P-value=0.003), fractionalshortening $(\mathrm{FS})(\mathrm{P}$-value $=<0.001)$ and right ventricular myocardial performance index (RMPI) $(\mathrm{P}$-value $=<0.001)$ werestatistically significant between two groups.Others echocardiographic parameters were notstatistically significant (P-value $>0.05)$.

Conclusion: the systolic and diastolic performance of thalassemia intermedia patients is affected earlier in comparison with control group in some parameters including LVMPI, EF, FS, IVSD, IVSS, LVPWDD and RVMPI. For more evaluation, more quantitative and comprehensive research suggested by evaluation of specific effective factors to psychosocial health of these patients.

\section{Study Limitation}

* Age group: we conduct only the pediatric age group thalassemia intermedia, and as we know the most of complication appear in older age

* Number of patient: we conduct only46 patient in our study.

*Lack of material potential: availability of other facilities like $\mathrm{T}^{*}$ and MRI as echocardiography is not able to replace them even echocardiographic abnormalities are found.

Key words:thalassemia intermedia in children, Complications of TI,cardiac function, echocardiography and Dopplerstudies. 


\section{Introduction}

B-Thalassemia is an inherited hemoglobin disorder caused by impaired synthesis of the b-globin chain and resulting in chronic hemolytic anemia (Modell \& Berdoukas, 1984). Depending on clinical severity, 2 forms thalassemia major (TM) and thalassemia intermedia (TI) are distinguished (Zurlo et al., 1989) .

TM is rapidly fatal unless adequate transfusions, in conjunction with intensive iron chelation therapy, are started early enough (Modell \& Berdoukas, 1984) .In contrast, TI is generally characterized by a mild clinical picture,better prognosis, and better chance for survival, and patients require therapeutic intervention only later in life (Ehlers et al., 2006).

Cardiac complications are a main feature of the clinical spectrum of $b$ thalassemia. They are the leading cause of death and have been well documented only in TM (Shawky \& Kamal, 2012). The prominent finding in this condition is left ventricle (LV) dysfunction which is attributed mainly to iron overload and leads gradually to cardiac failure and cardiogenic death (Marshall et al., 2006).

Although TM and TI share common basic pathophysiological mechanisms, cardiac involvement may be different in the latter because these patients live longer and generally have low hemoglobin levels and lower iron loads (Shawky \& Kamal, 2012).

By definition, the patients who spontaneously maintain hemoglobin at or above $7 \mathrm{~g} / \mathrm{dl}$, even at the price of bone marrow hyperplasia, characterized as thalassemia intermedia (Aessopos et al., 2009). The main reasons of early death in such patients concern the cardiac complications such as systolic and diastolic disorders caused by hemosiderosis (Aessopos \& Berdoukas, 2009).

The clinical picture of TI is dominated by the multiple long-term effects of chronic anemia and tissue hypoxia and their compensatory reactions, including enhanced erythropoiesis and increased iron absorption (Kanavakis et al., 2007). The former is expressed as bone marrow expansion and extramedullary hematopoiesis, leading in turn to bone deformities and to spleen and liver enlargement (Isner et al., 1982).

The main reasons of early death in thalassemia intermedia patients concern the cardiac complications such as systolic and diastolic disorders caused by hemosiderosis (Challenor et al., 2004).

The studies conducted so far indicated that the end-systolic and end-diastolic dimension index and also the whole heart index and systolic dimension of thalassemia intermedia patients have a significant increase compared with control group, it happens while the patients did not receive blood transfusion and did not show any clinical symptoms of cardiac disorder (Kanavakis et al ., 2007).

In the absence of regular treatment of thalassemia intermedia patients the diastolic performance of the left ventricle is maintained stable, while the pressure of pulmonary arteries continues to rise which is the main cause of death in these patients (Isner et al., 1982).

\section{Material and methods}

This case-control study was conducted on 46 thalassemic patients (mean age: $9.7 \pm 4.6$ years) group A and 46 healthy individuals (mean age: $10.3 \pm 4.1$ years) as a control group B, from October 2016 to September 2017 in the Pediatric haematology Clinics and inpatients of Pediatric Department. The patients were initially interviewed, clinically examined, and then 
underwent chest radiography and electrocardiography. Those participants who did not have any obvious cardiac disorder and patients who suffered from high blood pressure, metabolic, endocrine or kidney disorders or used to take heart drugs, or $\mathrm{Hb}<8 \mathrm{~g} / \mathrm{dl}$ were excluded from the study. 46 healthy children with the same age and gender that referred to our hospital for routine checkup were selected as control group. Written consent was obtained from each participant and the study was approved by the medical ethics committee of Sohag University of Medical Science. Both groups underwent echocardiography test by $2 \mathrm{D}$, Mmode, and Doppler methods and parameters such as Shortening fraction (SF), Ejection fraction (EF), Interventricular septal dimension in systole (IVSS),Interventricular septal dimension in diastole (IVSD), Left ventricular mass index (LVMI), left ventricular myocardial performance index (LMPI), , left ventricular

\section{Results}

The mean of the age in the group A was $9.7 \pm 4$.6years range from 1.5 to 17 years, while in the group $\mathrm{B}$ it was $10.3 \pm 4.1$ years range from 1.5 to 17 year $(\mathrm{P}-$ value $=0.592$ ). Comparison of age and gender revealed no significantly difference between two groups of case and control ( $\mathrm{P}$-value $>0.05$ ). The average of hemoglobin and hematocrit ingroup $\mathrm{A}$ and $\mathrm{B}$ were $8.7 \pm 0.5 \mathrm{~g} / \mathrm{dl}(33 \pm 1 \%)$ and $12.9 \pm 0.8 \mathrm{~g} / \mathrm{dl}$ $(34 \pm 3 \%)$ respectively. Table (2) represents the echocardiographic parameters of left ventricle in patient and control groups. The mean of left ventricular myocardial performance index (LMPI) ((P-value $<0.001)$ and left ventricular mass index (LVMI) $((\mathrm{P}-$ value $<0.001)$ havestatistically significant difference between two groups. Mean of interventricularseptal dimension in diastole (IVSD), left ventricular posterior wall thickness in diastole (LVPWD) and interventricularseptal dimension in systole (IVSS) were also statistically significant with a P-value of, <0.001, 0.042, <0.001 respectively. Ejection fraction $(\mathrm{EF})(\mathrm{P}$-value=0.003), fractional shortening (FS) (Pvalue $=<0.001$ ) and right ventricular myocardial performance index (RMPI) (Pvalue $=<0.001)$ were statistically significant between two groups. 
Table (1): comparison between cases and control groups regarding Age, gender, HB and HCT level:

\begin{tabular}{|c|c|c|c|}
\hline Parameter & $\begin{array}{l}\text { Cases } \\
(\mathrm{N}=46)\end{array}$ & $\begin{array}{c}\text { Control } \\
(\mathrm{N}=46)\end{array}$ & P-value \\
\hline $\begin{array}{l}\text { Age: } \\
\text { Mean } \pm \text { S.D. } \\
\text { (Range) }\end{array}$ & $\begin{array}{c}9.7 \pm 4.6 \\
1.5-17\end{array}$ & $\begin{array}{c}10.3 \pm 4.1 \\
1.5-17\end{array}$ & $0.592 *$ \\
\hline $\begin{array}{l}\text { HB (g/dl) } \\
\text { Mean } \pm \text { S.D. } \\
\text { Range }\end{array}$ & $\begin{array}{c}8.7 \pm 0.5 \\
8-9.8\end{array}$ & $\begin{array}{c}12.9 \pm 0.8 \\
10.9-14.5\end{array}$ & $<0.001 *$ \\
\hline $\begin{array}{l}\text { HCT \% } \\
\text { Mean } \pm \text { S.D. } \\
\text { Range }\end{array}$ & $\begin{array}{c}33 \pm 1 \\
24-33.8\end{array}$ & $\begin{array}{c}34 \pm 3 \\
34-49\end{array}$ & 0.123 \\
\hline
\end{tabular}

serum hemoglobin (HB),hematocrit level (HCT).

Table (2): Comparison between cases and control groups regarding Echocardiography examination:

\begin{tabular}{|c|c|c|c|}
\hline Parameter & $\begin{array}{c}\text { Cases } \\
(\mathrm{N}=46)\end{array}$ & $\begin{array}{c}\text { Control } \\
(\mathrm{N}=46)\end{array}$ & P-value \\
\hline $\begin{array}{l}\text { LVMPI } \\
\text { Mean } \pm \text { S.D. } \\
\text { Range }\end{array}$ & $\begin{array}{l}0.22 \pm 0.05 \\
0.14-0.31\end{array}$ & $\begin{array}{l}0.17 \pm 0.03 \\
0.11-0.28\end{array}$ & $<<0.001$ \\
\hline $\begin{array}{l}\text { RVMPI } \\
\text { Mean } \pm \text { S.D. } \\
\text { Range }\end{array}$ & $\begin{array}{l}0.34 \pm 0.08 \\
0.13-0.48\end{array}$ & $\begin{array}{l}0.49 \pm 0.03 \\
0.41-0.53\end{array}$ & $<0.001$ \\
\hline $\begin{array}{l}\text { IVSS }(\mathrm{mm}) \\
\text { Mean } \pm \text { S.D. } \\
\text { Range }\end{array}$ & $\begin{array}{c}10.6 \pm 1.5 \\
7-13\end{array}$ & $\begin{array}{c}8.8 \pm 2.5 \\
4-18\end{array}$ & $<<0.001$ \\
\hline $\begin{array}{l}\text { IVSD }(\mathbf{m m}) \\
\text { Mean } \pm \text { S.D. } \\
\text { Range }\end{array}$ & $\begin{array}{r}8.9 \pm 1.5 \\
5.5-12\end{array}$ & $\begin{array}{c}7.7 \pm 2.9 \\
3-18\end{array}$ & $<0.001$ \\
\hline $\begin{array}{l}\text { LVPWDD (mm) } \\
\text { Mean } \pm \text { S.D. } \\
\text { Range }\end{array}$ & $\begin{array}{c}6.2 \pm 2.5 \\
5-20\end{array}$ & $\begin{array}{c}4.8 \pm 1.6 \\
3-13\end{array}$ & 0.042 \\
\hline $\begin{array}{l}\text { EF\% } \\
\text { Mean } \pm \text { S.D. } \\
\text { Range }\end{array}$ & $\begin{array}{c}72.9 \pm 6.9 \\
59-86\end{array}$ & $\begin{array}{c}76.5 \pm 3.9 \\
69-84\end{array}$ & $\mathbf{0 . 0 0 3}^{*}$ \\
\hline $\begin{array}{l}\text { FS\% } \\
\text { Mean } \pm \text { S.D. } \\
\text { Range }\end{array}$ & $\begin{array}{c}42.6 \pm 6.6 \\
31-56\end{array}$ & $\begin{array}{c}47.8 \pm 4.7 \\
40-57.8\end{array}$ & $<0.001 *$ \\
\hline
\end{tabular}

$P$-Value was calculated by Mann-Whitney test* P-value was calculated by Independent-Samples $T$ test P-value <0.05 is significant.Shortening fraction (SF), Ejection fraction (EF), Interventricular septal dimension in systole (IVSS), Interventricular septal dimension in diastole (IVSD), Left ventricular mass index (LVMI), left ventricular myocardial performance index (LMPI), ), left ventricular posterior wall thickness in diastole (LVPWD) and right ventricular myocardial performance index (RMPI). 


\section{Discussion}

In this study, we have studied 46 thalassemia intermedia patients; their mean age was $9.7 \pm 4.6$ years which was lower compared with the patients who conducted in Nouri et al., 2013 and Vaccari et al., 2002 Studies which were $16.5 \pm 5.8$ years and $29.5 \pm 10$ years respectively; this is because our study conducted in pediatric age group. The mean serum hemoglobin level in our cases was $8.7 \pm \mathbf{0 . 5} \mathrm{g} / \mathrm{dl}$ ranging from 8 to $9.8 \mathrm{~g} / \mathrm{dl}$ which was lower than the mean serum HB level in control group that was $\mathbf{1 2 . 9} \pm \mathbf{0 . 8} \mathrm{g} / \mathrm{dl}$ ranging from 10.9 to $14.5 \mathrm{~g} / \mathrm{dl}$; the result similar to the result of Aessopos et al., 2005 and Mahdi et al., 2015 that showed also high serum HB level in cases than the control group.

That the mean hematocrit level (HCT) in case group was $\mathbf{3 3} \pm \mathbf{1} \%$ ranging from 24 to $\mathbf{3 3 . 8} \%$ that had no significant difference with the control group that was $\mathbf{3 4} \pm \mathbf{3} \%$ ranging from 34 to $49 \%$, the result similar to the result of Mahdi et al., 2015 study that showed also no significant difference between the case group and the control group.

The left ventricle myocardial performance index (LVMPI) among our patients was $\mathbf{0 . 2 2} \pm \mathbf{0 . 0 5}$ that was higher compared to control group $\mathbf{0 . 1 7}$ $\pm \mathbf{0 . 0 3}$, result similar to the result shown in Nouri et al, 2012 study which was $0.64 \pm \mathbf{0 . 6 1}$ that was also higher than their control group.

The mean right ventricular myocardial performance index (RVMPI) was $\mathbf{0 . 3 4}$ $\pm \mathbf{0 . 0 8}$ that was higher than control group that was $\mathbf{0 . 4 9} \pm \mathbf{0 . 0 3}$ coincide with the finding shown in Nouri et al, 2013 and Bosie et al., 2003studies.

The mean of inter ventricular septum in diastole (IVSD) of patient's group was $8.9 \pm 1.5 \mathrm{~mm}$ that was higher than control group $7.7 \pm \mathbf{2 . 9} \mathrm{mm}$ which is in agreement with the findings of Ocal et al., 2002 and the mean inter ventricular septum in systole (IVSS) in case group was $10.6 \pm 1.5 \mathrm{~mm}$ that was higher than control group $\mathbf{8 . 8} \pm \mathbf{2 . 5} \mathrm{mm}$ which is against with the findings of Bilge et al., 2010 that showed no significant difference between both group.

The mean Left ventricle posterior wall dimension in diastole (LVPWDD) was 6.2 $\pm 2.5 \mathrm{~mm}$ that was higher than control group $4.8 \pm 1.6 \mathrm{~mm}$ is against with the findings of Bilge et al., 2010 that showed no significant difference between both group, but our result in coincide with the finding showed in Nouri et al, 2013 and Aessopos et al., 2005 studies. And the mean left ventricular posterior wall dimension in systole (LVPWDS) was $7.9 \pm 2 \mathrm{~mm}$ that had no significant values with the control group $7.7 \pm \mathbf{2 . 1} \mathrm{mm}$; coincide with Nouri et al, 2013 study.

As regard the median of ejection fraction $(\mathbf{E F})$ it was $\mathbf{7 2 . 9} \pm \mathbf{6 . 9} \%$ that was slightly lower than control group 76.5 \pm 3.9 is against with the findings of Bilge et al., 2010 that showed no significant difference between both group, but our result in coincide with the finding showed in Aessopos et al., 2005 study which was $\mathbf{7 6} \pm \mathbf{5} \%$. The mean fractional shortening (FS) was 42.6 $\pm \mathbf{6 . 6} \%$ that was also slightly lower than control group $\mathbf{4 7 . 8} \pm \mathbf{4 . 7} \%$, result against with the findings of Bilge et al., 2010 that showed no significant difference between both group, but coincide with the finding showed in Aessopos et al., 2005 study which was $46 \pm 5 \%$.

\section{Conclusions:}

It can be concluded that systolic and diastolic performance of thalassemia intermedia patients is affected in comparison with control group due to parameters including MPI, EF, FS, IVSD, IVSS and LVPWD. For more evaluation, more quantitative and comprehensive research suggested by evaluation of specific effective factors 
to psychosocial health of these patients.

\section{Acknowledgment:}

Authors thank colleagues in the Pediatric Department, Faculty of Medicine, Sohag University (Egypt) for their assistance, and the parents and children who participated in this study.

\section{References}

1. Aessopos A, Farmakis D, Deftereos S, Tsironi M, Tassiopoulos $\mathrm{S}$, Moyssakis I, Karagiorga $M$. Thalassemia Heart Disease: A Comparative Evaluation of Thalassemia Major and Thalassemia Intermedia. Chest. 2005; 127(5):15231530.

2. Aessopos A, Berdoukas V. Cardiac function and iron chelation in thalassemia major and intermedia: a review of the underlying pathophysiology and approach to chelation management. Mediterranean Journal of Hematology and Infectious Diseases.2009; 49 (2):137-143.

3. Aessopos A, Tsironi M, Andreopoulos A, Farmakis D. Heart disease in thalassemia intermedia. Hemoglobin. 2009; 33(1):170-6.

4. Bosi G, Crepaz R, Gamberini MR, Fortini M, Scarcias, Bonsante E. Left Ventricular remodeling and Systolic and diastolic Function in young adult with beta thalassemia Major: A Doppler echocardiographic assessment and correlation with hematologic data. Heart. 2003; 89(7):262-6.

5. Challenor VF, Conway N, Monro JL. The surgical treatment of restrictive cardiomyopathy in pseudoxanthoma elasticum. Br Heart J. 2004; 59:266269.

6. Ehlers KH, Levin AR, Markenson AL. Longitudinal study of cardiac function in thalassemia major. Ann N Y Acad Sci. 2006; 344:397-404.

7. Isner JM, Carter BL, Bankoff MS, Konstam MA, Salem DN. Computed tomography in the diagnosis of

\section{Conflict of Interest:}

There is no conflict of interest to be declared.

\section{Authors contributions:}

All authors contributed to this project and article equally. All authors read and approved the final manuscript.

pericardial heart disease. Ann Intern Med.1982; 97:473-479.

8. Kanavakis E, Traeger-Synodinos $\mathbf{J}$, Tzetis M, Metaxotou-Mavromati A, Ladis V, Kattamis C.Molecular characterization of homozygous (high hba2) beta-thalassemia intermedia in Greece. Pediatric Hematol Onco. 2007;1:135-158.

9. Mahdi, Safa A, Laith S, Faraj, Hasanein H, Ghali. Significance of Red Blood Cell Indices in BetaThalassaemia Trait. Mustansiriya Medical Journal.215; 14:27-30.

10.Marshall A. Lichtman Ernest Beutler, Thomas J.Williams. Hematology. In: Kaushansky SK, Josef T.7th ed. 2006: 633-6.

11.Modell B, Berdoukas V. The Clinical Approach to Thalassemia. New York, NY: Grune \& Stratton.1984.3:115-130.

12.Nouri NM, Naderi M, Emamdadi A, Fadaie M, Rajaie S. Comparison of Cardiac Function in Young Patients with Thalassemia Intermedia and Healthy Individuals Using Echocardiography Method. Iranian journal of blood and cancer. 2012; 4(4):157-161.

13.Nouri NM, Naderi $M$, Rajaie $S$, Dorgalaleh A , Tabibian Sh. Evaluation of Cardiac Function in Patients with Thalassemia Intermedia. Iranian Journal of Pediatric Hematology Oncology. 2013; 13 (1):193-199.

14.Ocal B, Oguz D, Karademir S, Birgen D, Yüksek N, Ertem U. Myocardial performance index combining systolic and diastolic 
myocardial performance in doxorubicin-treated patients and its correlation to conventional echo/Doppler indices. Pediatr Cardiol. 2002; 23(5):522-7.

15.Shawky RM, Kamal TM. Thalassemia intermedia: An overview. Egyptian Journal of Medical Human Genetics. 2012; 13: 245-255.

\section{Vaccari $M$, Crepaz $R$, Fortini $M$,} Gamberini MR, Scarcia S, Pitscheider W, Left ventricular remodeling, systolic function and diastolic function in young adults with beta thalassemia intermedia: a Doppler echocardiography study. Chest 2002; 121(2): 506-12.

17.Zurlo MG, DE Stefano P, BorgnaPignatti. Survival and causes of death in thalassemia major. Lancet. 1999; 2:27-30. 